\title{
Lamoso, Adriana, Ezequiel Martínez Estrada: cultura, política y redes intelectuales, Ciudad de México, Bahía Blanca, Argentina, Centro de Investigaciones sobre América Latina y el Caribe (CIALC)-UNAM, Editorial de la Universidad Nacional del Sur(Ediuns)- Fundación Ezequiel Martínez Estrada, 2017, 243 pp. ISBN: 978-987-655-145-8.
}

\section{Marta Susana Dominguez*}

Adriana Lamoso es doctora en Letras por la Universidad Nacional del Sur, Bahía Blanca, en donde es investigadora y profesora. Ha sido distinguida con diversas becas, premios y reconocimientos, tanto en Argentina, como en México y Alemania. Es investigadora del Centro de Estudios Interdisciplinarios sobre Nuestra América "José Marti'” (CEINA); del Centro de Estudios Regionales "Félix Weinberg" (CER); es miembro del Consejo Directivo de la Fundación Ezequiel Martínez Estrada e integra la red "El ensayo en diálogo". Está especializada en los ensayos de interpretación de Ezequiel Martínez Estrada, prosa de ideas, pensamiento político, redes e historia intelectual en América Latina. Realizó estancias de investigación, dictó conferencias y cursos en la unAm, El Colegio de México, CIESAS, Casa de las Américas, Freie Universität Berlin, Universität Potsdam, Katholieke Universiteit Leuven, Université Michel de Montaigne Bordeaux 3, Universidad Internacional Menéndez Pelayo, entre otras. Cuenta con numerosas publicaciones en libros y revistas especializadas.

Este nuevo libro sobre Ezequiel Martínez Estrada viene a completar y a ordenar importantes estudios sobre su vida y obra. Consta de una introducción, doce capítulos y las conclusiones. Está precedido de un valioso prólogo de la doctora Liliana Weinberg.

* Departamento de Humanidades, Universidad Nacional del Sur (UNS), Bahía Blanca, Argentina, correo electrónico: mdominguez@uns.edu.ar. 
Lo medular del estudio de la doctora Lamoso, quien insumió años de rigurosas investigaciones, es la indagación de los sentidos y alcances de la auto-percepción intelectual del escritor. Su trabajo consiste en definir distintos períodos que implican cambios en lo que respecta a su modo de leer la literatura, el rol social y político de los actores culturales, que vincula con el estudio de autores como Sarmiento, Hernández, Leopoldo Lugones, Horacio Quiroga, Nietzsche y otros, con la interpretación de la historia, y con la peculiaridad de la inserción del ensayista en redes de sociabilidad intelectual. Martínez Estrada lee los escenarios político-ideológicos de Argentina y de América Latina, a través de su paso por México y Cuba, mediado por sus tomas de posición estético-culturales que se asocian a la figura del escritor propuesta por Julien Benda e incluye su giro a la figura sartreana del intelectual comprometido.

La autora realiza un exhaustivo recorrido por la producción ensayística de Martínez Estrada, determinando diferentes etapas. La primera tiene asidero en la crisis del '30, con el estudio interpretativo de ensayos resonantes como Radiografía de la pampa, La cabeza de Goliat, El hermano Quiroga y Leopoldo Lugones, retrato sin retocar, en los que el autor lee diferentes problemáticas como sus preocupaciones inherentes al proceso de profesionalización del escritor argentino, que se tensa con la red que integró junto a Lugones, Quiroga, Franco y Glusberg; la segunda corresponde a los textos que publica en el período de posguerra y la reciente asunción del gobierno del general Perón, como su Sarmiento, Los invariantes históricos en el 'Facundo'y Nietzsche; Muerte y transfiguración de 'Martín Fierro' es caracterizado por la doctora Lamoso como un texto "bisagra", en tanto articula matrices de pensamiento que abrevan sus aguas en escritos precedentes, al tiempo que incluye categorías analíticas que profundizará en las décadas siguientes; el núcleo de ensayos editados en la etapa posperonista recrudece su forma en consonancia con la preocupación creciente por los escenarios de la política de Argentina, se trata de ¿Qué es esto? Catilinaria, Las 40, Exhortaciones y Cuadrante del Pampero; los años 1959 y 1960 representan un punto de quiebre que implica la salida del país por parte del escritor hacia Europa, Chile, México y Cuba. Este último período incluye su apertura a América Latina y el Caribe, ya iniciada en la década del '40, así como un vigoroso giro ideológico en su adhesión a la Revolución Cubana. Se destacan los textos Análisis funcional de la cultura, Para una revisión de las letras argentinas, Diferencias y semejanzas entre los países de América Latina, el "Prólogo inútil" de su Antología, así como los discursos publicados en Cuadernos Americanos. Es en esta etapa, según la fina interpretación de la doctora Lamoso, cuando comienza una "operación de legitimación de su obra precedente". El estudio de las redes intelectuales le permitió a la investigadora reinsertar la frondosa y compleja producción ensayística global de Ezequiel Martínez Estrada en el entramado de variados y densos procesos, que lo fueron recolocando en el campo de la cultura latinoamericana, en particular, a partir 
de los estrechos vínculos mantenidos con los directores sucesivos del Fondo de Cultura Económica de México, Daniel Cossío Villegas y Arnaldo Orfila Reynal. Resulta un aporte fundamental verlo, entonces, como un autor en diálogo no sólo intelectual sino editorial y epocal. Asimismo, la reconstrucción de este camino sinuoso permitirá un posterior estudio de la aún poco explorada "etapa cubana" de Ezequiel Martínez Estrada. 